\title{
O patrimônio digital e as memórias líquidas no espetáculo do instagram
}

\author{
Stphanie Sá Leitão Grimaldi ${ }^{I}$ \\ http://orcid.org/0000-0002-5586-7563 \\ Maria Nilza Barbosa Rosa II \\ http://orcid.org/0000-0002-2476-2793 \\ José Mauro Matheus Loureiro ${ }^{I I I}$ \\ Bernardina Freire de Oliveira ${ }^{\text {IV }}$ \\ http://orcid.org/0000-0002-6836-3102
}

${ }^{I}$ Universidade Federal da Paraíba, João Pessoa, PA, Brasil.

Doutoranda no Programa de Pós-Graduação em Ciência da Informação.

${ }^{\text {II }}$ Universidade Federal da Paraíba, João Pessoa, PA, Brasil.

Pós-doutoranda no Programa de Pós-Graduação em Ciência da Informação.

III Universidade Federal do Estado Rio de Janeiro, Rio de Janeiro, RJ,Brasil.

Docente na Universidade Federal do Estado do Rio de Janeiro e do Programa de

Pós-Graduação em Ciência da Informação da Universidade Federal da Paraíba.

IV Universidade Federal da Paraíba, João Pessoa, PA, Brasil.

Docente no Programa de Pós-Graduação em Ciência da Informação.

\section{http://dx.doi.org/10.1590/1981-5344/3340}

Aborda o patrimônio digital, sua constituição na memória social de determinados grupos, sua possível constituição identitária e a razão de sua preservação e disseminação, baseada na cultura e na significação atribuídas aos patrimônios tomados pela informação digital na modernidade líquida. Tem como objetivo problematizar os limites (in)existentes para disseminação e para a preservação das informações em meio digital, com foco na salvaguarda e perpetuação da memória social dos referidos patrimônios. Circunscritos em um regime de informação singular no ambiente da cultura virtual, ou cibercultura, os patrimônios digitais, por meio da informação digital, atuam como um sistema condicionado e condicionante dos sujeitos contemporâneos, impondo à busca por identidade um vínculo diferente e multifacetado do ordinário. Utilizou-se da rede social Instagram como 
objeto de estudo e a aplicação do questionário para coletar informações sobre a utilização do Instagram para fins memoriais através do perfil selecionado (geração $Y$ e $Z$ ). Como resultado, foi identificado o impacto cotidiano da rede social Instagram nos sujeitos e suas relações, suas práticas de divulgação de espaços culturais, a intencionalidade das postagens e na constituição de suas memórias.

Palavras-chave: Memória Social. Patrimônio Digital. Cibercultura. Identidade. Instagram.

\section{The digital heritage and the liquid memories in the instagram show}

Addresses the digital heritage, its constitution in the social memory of certain groups, it's possible identity constitution and the reason for its preservation and dissemination, based on the culture and meaning attributed to the heritage taken by digital information in liquid modernity. Its objective is to problematize the (in) existing limits for the dissemination and preservation of information in digital media, focusing on safeguarding and perpetuating the social memory of these assets. Circumscribed in a unique information regime in the environment of virtual culture, or cyberculture, digital heritage, through digital information, acts as a conditioned and conditioning system of contemporary subjects, imposing a different and multifaceted bond to the search for identity. The Instagram social network was used as the object of study and the questionnaire was applied to collect information about the use of Instagram for memorial purposes through the selected profile (generation $Y$ and $Z$ ). As a result, we identified the daily impact of the Instagram social network on the subjects and their relationships, their practices of dissemination of cultural spaces, the intentionality of the posts and the constitution of their memories.

Keywords: Social Memory. Digital Patrimony. Culture. Identity. Instagram.

Recebido em 17.11.2017 Aceito em 02.09.2019 


\section{Introdução}

A categoria de "patrimônio", anteriormente ligada de forma direta e assimilativa a pedra e cal, foi (re)categorizada e evocou novos contornos semânticos, diversos e específicos, no decorrer dos tempos de acordo com o contexto envolvendo o momentum (CHOAY, 2006; ABREU, 2015). Ao sair da limitação do concreto, o patrimônio encontrou o intangível existente no mundo físico, em um diálogo permanente entre materialidade, imaterialidade e sua coexistência. Entretanto, devido a sua metamorfose semântica, agregado ao seu sentido de existência, o qual deve se ligar irremediavelmente ao contexto temporal vigente, impondo novas categorias ou apropriações, outras categorias continuam a se apropriar do patrimônio, tonando-se inerentes a ele, dentre elas a informação, em todos os meios, incluindo o digital.

A informação, por ser relacional é um acontecimento que afeta o meio dissolvendo-o, alterando, subvertendo e destruindo o desconhecido e as coisas indeterminadas. É, assim, a diferença que faz a diferença, ou mesmo uma diferença que encontra uma diferença (CAPURRO; HJORLAND, 2007). Essa diferença representa o outro, a alteridade, multiplicidade e heterogeneidade, que ao dialogar com o patrimônio, encontra no meio digital, um ambiente fluido, terreno fértil.

Por meio dessa interseção entre patrimônio e informação, incluindoa em meio digital ou virtual, a Ciência da Informação, pelo seu agenciamento humano, enxerga seu objeto de estudo, assim como definido por Le Coadic (2004): a informação em ambientes específicos. Faz-se presente então a necessidade do estudo dos processos de construção, comunicação e uso da informação e a concepção dos produtos e sistemas que permitem sua construção, comunicação, armazenamento e utilização. Em todas essas instâncias, a disseminação e a preservação da memória social encontram-se incluídas.

O contexto social do século XXI subscreve-se por meio da tecnologia, não sendo mais uma novidade a transição dos objetos analógicos para o meio digital, ou mesmo sua concepção nesse ambiente. Contudo, não é apenas uma parcela social que está transitando entre analógico e digital, mas toda a cultura contemporânea, a qual está submetida a esta flutuação entre esses dois aspectos pragmáticos, dando origem a uma cibercultura e a um ciberespaço. Não obstante, dentro desse espaço, também se situa o conceito de patrimônio, que é infligido e apropriado pelo contexto, bem como a informação.

$\mathrm{Na}$ contemporaneidade, marcada por um ritmo acelerado de transformações, agravada pela temporalidade mítica do digital, a memória social opera como fator de aglutinação das diferenças, as quais tendem a se multiplicar na virtualidade. Quanto mais velozes as mudanças sociais ("na febre ou na angústia"), assevera Le Goff (2003), mais essencial é a busca pela memória. Tal busca, para Gondar (2005), se configura na memória social, a qual se apresenta como uma memória processual cujos elementos emergem da mescla entre memórias individuais e coletivas tornando-as, assim interdependentes. Essa proposição dialoga com o 
entendimento de Diehl (2002, p. 121) para quem a memória constitui-se "uma representação daquelas experiências vividas por homens numa dimensão social", uma memória que depende da cultura na qual está inserida.

Na antropologia, na ciência ou nas artes, a importância da cultura é fundamental à sociedade, pois seu relacionamento se dá de maneira íntima a todas as atividades na qual o ser humano se envolve e modifica seu espaço, além de ser gerador de como o ser humano visualiza e manipula os produtos ou objetos produzidos socialmente. Para alguns estudiosos, por exemplo, Geertz (1978) e Bauman (2001), o uso da cultura sempre foi fundamental à explicação dos fenômenos sociais, ainda que observados de formas diferentes.

Assumida nessa pesquisa como insumo da memória, a cultura exerce papel essencial e fundamental em estudos memorialísticos e patrimoniais. Compreendemos assim a cultura como sistema simbólico que permeia as atribuições de valores de todos os segmentos sociais na qual o homem se insere e modifica seu espaço, influenciando de forma direta a memória e a preservação ou disseminação de seu patrimônio, inclusive na era digital, por meio de uma cibercultura.

Desse modo, a discussão presente nesta pesquisa gira em torno do patrimônio digital, tomado pela informação digital, representado em fotografias, sua constituição na memória social, sua possível construção identitária e da razão de sua preservação e disseminação, tendo como base a cultura (cibercultura) e a significação atribuída aos patrimônios digitais, na atual era do espetáculo. Para tanto, escolhemos utilizar como objeto de estudo nesta pesquisa o Instagram, rede social a qual é alimentada diariamente com fotos e vídeos, pessoais e públicos, por mais de 1 (um) bilhão de usuários, sendo o Brasil o segundo país em utilização.

Circunscritos em um regime de informação singular no ambiente da cultura virtual, os patrimônios digitais, atuam como um sistema condicionado e condicionante dos sujeitos contemporâneos, impondo à busca por identidade um vínculo diferente e extraordinário, onde a vida real, aquela vivida em meio analógico, mescla-se com a vida espetáculo, a qual pode ser postada, editada, apagada e repostada, gerando memórias líquidas e identidades multifacetadas, por meio da informação digital.

Desde o aparecimento do ambiente virtual na década de 80 do século passado, a informação vem se tornado a cada dia mais digital, levando a Ciência da Informação (CI) em seu encalce. Gantz (2008) nos informa que durante o ano de 2006, onde ocorreu um impacto informacional em ambiente virtual, mais de 160 milhões de gigabytes (GB) de informação digital teriam circundado a Terra. Para o autor ocorreu uma verdadeira explosão do universo digital, no que se refere à informação.

Com a emergência da tecnologia e do crescente número de usuários das redes, uma nova faceta, no que se refere ao registro da informação, ocorre, segundo Pinto (2009), acarretando em uma mudança na forma de registro e consequentemente na forma de comunicação informacional. 
De acordo com a previsão feita no estudo de Gantz e Reinsel (2012), entre os anos de 2005 a 2020, o universo da informação digital vai acender por um fator de 300 (de 130 exabytes para 40.000 exabytes), isso equivale a 40 trilhões de gigabytes (mais de 5.200 gigabytes para cada indivíduo em 2020). Ou seja, até 2020, a informação digital duplicará a cada dois anos.

Entretanto, vale fazer uma ressalva, como lembram Siebra, Borba e Miranda (2016) que, apesar de grande parte do aumento do fluxo de informação ser de informação de gênese digital, uma significativa parte da vastidão da informação digital resulta, também, de iniciativas de conversão de dados analógicos.

Logo, onde antes contávamos apenas com registros em suportes tradicionalmente analógicos, atualmente contamos com registros inscritos em plataformas por dispositivos constituintes dos sistemas tecnológicos de informação. Prontamente, passamos de um produto bidimensional informação-suporte -, para um produto tridimensional - informaçãosuporte-tecnologia (SILVA, 2006).

Por essa definição do autor supracitado, consideramos nessa pesquisa que mesmo em meio digital, a informação possui um suporte, não podendo assim ser considerada neutra e destituída de forma. Apesar de fugir ao tradicional objeto palpável, como livros que podem ser impressos, os vídeos que podem ser gravados em cassetes ou $d v d$ 's, a informação digital mantém sua materialidade ligada a sua existência.

Alguns autores, como Bellotto (2014) afirmam que os documentos digitais, ou mais amplamente as informações digitais, não possuem existência física a não ser que sejam impressos. Discordamos desse pensamento e corroboramos ao pensamento de Pinto (2009), autora que afirma que ao pensarmos desse modo voltamos aos princípios do paradigma custodial, onde eram exigidos manuseio e manipulação palpável, além disso, quebramos algo importante do paradigma póscustodial, o qual ganha total liberdade de existência no ambiente cibercultural. Para a autora o suporte da informação e documento digital ${ }^{1}$ é "de facto o ambiente digital" (PINTO, 2009, p.116). Dodebei (2011) corrobora a esse pensamento e afirma que devido à materialidade das informações digitais, elas constituem, inclusive, parte da cultura material.

Nesse sentido, observamos que a informação digital, pode ser encontrada nas mais variadas representações. Ou seja, a informação digital pode aparecer em formato de texto, vídeo, imagem, áudio, dentre outras variadas configurações, e todas são tomadas como objetos de estudo pela Ciência da Informação, mesmo que não se utilizem do termo informação digital. Essa apreensão amplia a complexidade da relação entre memória, patrimônio cultural, informação digital e redes sociais, ambiente que engloba os três primeiros fatores.

\footnotetext{
1 Quando falamos em informação digital, diferenciamos apenas de informação eletrônica, essa última a qual surgiu em um período onde as máquinas ainda eram dependentes da realidade, ou seja, careciam de uma gravação, reprodução ou materialização em suportes analógicos como fitas, impressões etc.
} 
Com essas observações, consideramos assim que a informação digital, objeto de estudo primordial da CI, é matéria prima da cibercultura, composta pela heterogeneidade de elementos, contextos, sujeitos e micropoderes, constituintes do que podemos chamar de Patrimônio Cultural Digital representação responsável pela preservação da memória social.

\section{Cultura, cibercultura e significação}

Historicamente, o conceito de cultura já foi objeto de estudo de variados e renomados estudiosos das Ciências Sociais, que buscavam entender as origens mais intrínsecas ao homem e seu ambiente social, origens essas que tornam o ser humano um enigma para os outros iguais a ele. Por conseguinte, não podendo ser de modo diferente, levando em consideração a complexidade da realidade sociocultural, seu entendimento e reflexão sofreram variações, tanto em extensão como em aplicação, de modo que este fenômeno alcança o século XXI por meio de importantes pesquisas sobre o tema. São múltiplos os questionamentos sociais sobre 0 que realmente pode-se nomear de cultura, ou culturais.

No entanto, essas variações, devido a sua abrangência conceitual, nem sempre proporcionam uma melhor clarificação que auxilie os mencionados questionamentos, o que para Geertz (1978) acabou por agregar ao termo uma aura de má reputação, perante os antropólogos sociais, no que se refere a sua evocação em demasia.

Com a fluida acepção contemporânea, o conceito recebeu no decorrer do tempo, novas, constantes e diversificadas definições, devido ao interesse crescente no tema. Desse modo, ao invés de contribuir com uma melhor compreensão do assunto, fundamental às pesquisas socioculturais contemporâneas, ocasionou, segundo Laraia (2001), uma amplificação que mais serviu para confundir do que para esclarecer o conceito. Cultura se tornou algo tão amplo, que sua extensão conceitual pode abarcar tudo, o que acarreta em muitas vezes nada dentro dos questionamentos socioculturais. Para Geertz (1978) a contração conceitual do termo é essencial para tornar o conceito poderoso teoricamente.

Essa abrangência terminológica, quando situada nas sociedades contemporâneas, acaba por agravar os problemas sociais instaurados nas comunidades. Isso decorre do fato de os estudos socioculturais serem 0 alicerce para a resolução de tais problemas, que sem uma base teórica concreta, podem acabar por culminar na ineficácia das iniciativas geradas a partir desses estudos. Essa necessidade se amplia quando relacionada a termos tão influenciadores como, por exemplo, o conceito de cultura.

Posto isto, faz-se necessário evidenciar de que maneira a cultura (ou culturas), será abordada nesta pesquisa, de modo a evitar flutuações conceituais e tornar o termo mais disposto e sistêmico, devido a sua instabilidade. Sendo a cultura um sistema complexo onde, segundo Laraia (2001), não existe a possibilidade de um individuo dominar todos os seus aspectos, em qualquer tipo de sociedade, delimitamos o estudo no que se 
refere à sua relação teórico-conceitual das culturas com a memória e o patrimônio.

Assume-se assim a definição dada por Geertz (1978, p. 9), na qual leva em consideração a semiótica, sendo a cultura um documento de atuação constituída em estruturas de significados socialmente estabelecidos, definidas em um contexto. Ou seja, a cultura se constitui em

um padrão de significados transmitidos historicamente, incorporado em símbolos, um sistema de concepções herdadas expressas de forma simbólica por meio do qual os homens se comunicam, perpetuam e desenvolvem seu conhecimento e suas atividades em relação a vida (GEERTZ, 1978, p. 66).

Esse pensamento de Geertz leva em consideração os pensamentos de Max Weber, na qual o homem é um animal amarrado a teias de significados, sendo a cultura essas teias e sua análise. Essa visão tem como fundamento a semiótica, que busca um estudo interpretativo dos significados dos símbolos (tomado pelo autor como todo e qualquer objeto, ato, acontecimento, qualidade ou relação que serve como vínculo a uma concepção). Sendo assim, apresenta a cultura como a base para as formulações de mundo que o ser humano irá desenvolver e por consequência se refletirá em todas as áreas na qual se relacionar socialmente. São estruturas estruturantes, mas não estruturadas (SCHWARTZMAN, 1997).

Portanto, a cultura é algo público, bem como seu significado, não definido geneticamente, mas construído e vivenciado socialmente. De modo a comprovar que a cultura pouco tinha a ver com determinações genéticas, biológicas ou geográficas (deixando de lado as estruturas estruturadas de padrões concretos de comportamento), como algumas teorias chegaram a preconizar, o campo cultural se aproximou cada vez mais da Ciência, por meio de estudos e investigações. Tal aproximação resultou em uma relação quase indissociável, sendo para Turgot (1780 apud LARAIA, 2001) e para Geertz (1978) o conhecimento e as ideias produzidas pelo homem constituintes de uma herança cultural em permanente crescimento, um patrimônio. Esta ideia inicia-se com o pressuposto de que o pensamento não ocorre de maneira privada, "na cabeça", mas sim no ambiente social, tendo a capacidade de reter e disseminar as informações pelas futuras gerações (de forma memorial), onde os dados já estão dispostos em uso corrente na comunidade. 0 homem os retém, os utiliza, os modificada e os dissemina socialmente. Sem tais padrões culturais (sistemas organizados de símbolos com significados) o comportamento humano seria um caos de atos sem sentido, em uma experiência sem forma, o que evidencia a cultura como uma condição essencial à existência humana, não existindo natureza humana independente da cultura (GEERTZ, 1978). 
Esses pensamentos constroem uma linha de raciocínio que evidenciam o papel da cultura na constituição da mentalidade humana, sendo a cultura um agente modificador do ser humano, na medida em que vão ocorrendo aprendizados de significados ou alterações significantes. Neste sentido, o que tem relevância para o ser social em tudo depende da significação dada ao objeto em questão, pois a cultura humana é um ingrediente basilar ao pensamento e não apenas seu suplemento. Para Schwartzman (1997), tais significações servem de estratégias de organização e ação social e, como tais, estão sujeitas a serem adotadas, modificadas, ou deixadas de lado, de acordo com a apreensão significativa das pessoas que as adotam.

Como consequência desse sistema de significação, o ser humano se depara com indagações ou problemas motivadores de sua natureza, questionamentos inerentes ao ser. Para Geertz (1978), neste momento, inicia-se uma busca por informações que visem tornar a situação coerente e organizada, visto que o homem não está preparado para o caos. Por meio da manipulação dos recursos culturais, são produzidos estímulos no ambiente em uma incessante busca informacional para solucionar tais problemas, principalmente os de ordem emergencial. A relação entre cultura e informação se dá em sua própria natureza, sendo a cultura uma depositária da informação produzida socialmente, podendo ser considerada como a genoteca ${ }^{2}$ da sociedade humana (MARTELETO, 1995).

O que muda na contemporaneidade é a natureza da informação. O ambiente antes estático e sólido, agora é leve, líquido, fluido e dinâmico, assim como a cultura, as relações e seus objetos (BAUMANN, 2001). Ainda segundo o autor, a nova modernidade, impõe mudanças de forma constante, exigindo uma permanente adaptação. O que mais vale é o tempo de resposta, não mais o espaço de ocupação. No momento em que a cultura é tomada como depositária informacional e a informação tem seu gene alterado, parcialmente ou totalmente, a cultura a segue e se adapta. Esse fenômeno é observado no meio virtual, tomado por bits informacionais que se mesclam a cultura dominante.

Esse processo sociocultural de adaptação e integração da vida com as tecnologias informacionais e comunicacionais é nomeado por Lemos (2002), de cibercultura. Para Castells (2007), o conceito formula-se a partir da alteração do significado do termo informática, que anteriormente opunha o homem à máquina, em uma relação opressiva e subjugada do primeiro pelo segundo, sucedendo a uma relação de convergência com a tecnologia, proporcionando ao homem a utilização das capacidades maquinárias tecnológicas. Tais aparatos compreendem desde computadores, smart phones à smart $t v$ 's, todos interconectados por meio da internet.

20 termo "genoteca" foi empregado por Edgar Morin referindo-se ao sistema social o qual por meio de uma memória ou um repertório cultural (a genoteca) evidencia-se quando todo o sistema estiver em operação, com conjuntos de mensagens envolvidas de forma quase programática. MORIN, Edgar. Sociologia. Paris: Fayard, 1984, p.92-93. 
Assim, ambientada na rede mundial de computadores, a cibercultura é definida por Lévy (2007, p.17) como o tempo da conectividade, interação e difusão de informações, referindo-se ao "conjunto de técnicas (materiais e intelectuais), de práticas, de atitudes, de modos de pensamento e de valores que se desenvolvem juntamente com o crescimento do ciberespaço". Ainda segundo o autor, o ciberespaço configura-se como o contemporâneo meio comunicacional que emerge do world wide web, indo além da dos hardwares e softwares, dependente principalmente das informações e de seus agentes, os seres humanos, tendo como palavras de ordem a interconexão, a criação de comunidades virtuais e a inteligência coletiva.

Destarte, no que concerne a esta pesquisa, seguindo a estreita relação entre cultura e informação, inclusive a digital, tomando as visões antropológicas compartilhadas por Geertz (1978), Laraia (2001), Lemos (2002), Castells (2007) e Lévy (2007), assumimos a possibilidade das informações em meio digital serem tomadas como patrimônio, constituintes da memória social de determinados grupos, advindas das ações simbólicas da cultura, sendo o sistema simbólico a essência da memória (BARBOSA, 1998). Partilhamos do entendimento do sistema simbólico de Deleuze e $n$ (1997), onde englobam-se as tecnologias da informação e comunicação, entidades materiais, visto que as semióticas são inseparáveis dos componentes materiais. Faz necessário assim, uma análise da configuração atual dessa relação, no momento em que a dinâmica ordinária muda no elo entre cultura ou cibercultura, memória e patrimônio. Todavia, não haveria espaço melhor para se debater tais mudanças do que nas redes sociais, atual ambiente de encontro e sociabilidade dos sujeitos, nativos ou emergentes digitais que depositam seus patrimônios e suas memórias episódicas e as tornam leves e fluídas.

\section{Patrimônio cultural digital}

A categoria de "patrimônio" adquiriu diversos contornos semânticos em diferentes épocas e campos do conhecimento. A construção da ideia de patrimônio no Ocidente vincular-se-ia à necessidade dos grupos sociais preservarem sua origem e genealogia. No caso do patrimônio cultural seu significado contemporâneo foi cunhado por meio de agências nacionais e internacionais, políticas públicas, formação de agentes especializados, dentre outros. Apesar de todas as ações essa noção permanece como um campo de disputas conceituais acirradas e de busca por um circuito próprio de circulação de ideias, práticas e profissionais. Segundo Geertz (1978), por exemplo, o mundo encontra-se "em pedaços" e os patrimônios repercutem essa fragmentação, tornando-se eles próprios frações evocativas de uma totalidade que acaba sempre por ser adiada. Sua trajetória é, portanto, complexa exigindo um desenvolvimento teórico permanente. Para os fins aqui propostos o patrimônio cultural é entendido como um conjunto de representações, símbolos e práticas que traduzem a cultura e a identidade de grupos ou da nação. 
O que se pode constatar é que as abordagens ao patrimônio cultural são, quase sempre, acompanhadas de perspectivas vinculadas à preservação, isto é: ideias ou ações de prevenção, proteção, conservação, protegendo de danos ou perigos futuros. Para Dodebei (2008) isso se dá, pois os denominadores comuns que existirão em todo e qualquer patrimônio são os da herança, tradição, conhecimento, experiência, legado, vivência, entre outras expressões que denotam a ideia de transmissão natural da cultura, de uma geração à outra.

De acordo com Chagas (2003, p.164-165), "a preservação participa de um jogo permanente com a destruição, um jogo que se assemelha, totalmente, ao da memória com o esquecimento". É a partir do medo da destruição dos objetos a que se atribui valor, que os sujeitos sociais mobilizam-se na busca de meios de preservação. Inversamente, é na ausência da atribuição de valor que a destruição ou esquecimento substitui a preservação, pois "é preciso que o sujeito da ação identifique no objeto a ser preservado algum valor" (CHAGAS, 2005, p. 118).

Essa relação dos patrimônios, seus denominadores comuns e 0 ímpeto preservacionista sofrem um impacto quando presente no ciberespaço, movido por informações digitais. Uma nova relação entre patrimônio, informação digital e preservação é delineada, não enclausurada pelos denominadores comuns do patrimônio, originalmente de pedra e cal. Isso se dá pela própria natureza da informação digital, e do fluxo existente no ciberespaço, agora dominada por um cibercultura que remodela valores e objetivos sociais, acarretando em vantagens e desvantagens para o campo patrimonial. Tal relação ainda não é totalmente delineada, mas exige atenção, dada a situação efêmera do patrimônio digital.

Ao longo dos últimos sete anos, as pesquisas envolvendo a relação entre informação, memória e ciberespaço ganharam maior visibilidade dentro da Ciência da Informação no Brasil, com a inclusão do grupo temático Informação e Memória no Encontro Nacional de Pesquisa em Ciência da Informação (ENANCIB), motivados pelas circunstâncias impostas pela virtualidade, considerando a intrínseca relação entre memória e contexto.

Lazzarin, Azevedo Netto e Sousa (2015), em uma pesquisa sobre a temática da inclusão do ciberespaço nos estudos da memória na área de Ciência da Informação, concluem que a memória social é uma das maiores fontes de discussão nos artigos do ENANCIB, quando alinhada a temática do ciberespaço. Sendo assim, para os referidos autores, o espaço virtual tornou-se um grande propagador e facilitador da memória social, além de um tesouro para a preservação da memória, mediante manifestações e ações dos profissionais da área.

Não configura surpresa neste sentido a relação da apropriação do patrimônio cultural na área, já tomado pela contextualidade do ambiente virtual, tendo em vista que a mesma é um importante constituinte da memória social e, consequentemente, da identidade coletiva. 
Contudo, é possível verificar nos estudos de Dodebei (2011) e Lazzarin, Azevedo Netto e Sousa (2015), que as pesquisas sobre a memória social no ciberespaço, levando em conta o patrimônio cultural e digital, ainda são incipientes. Quando os patrimônios são inseridos na relação tempo-espaço imposta pela virtualidade do ambiente virtual, os riscos impostos são maiores devidos à efemeridade e circunstancialidade próprias das tecnologias, que necessitam de práticas curatoriais (MONTEIRO; CARELLI; PICKLER, 2006) ou disseminadoras específicas. Lévy (2007) em seus estudos sobre a importância de estudar as imposições do meio digital, já informava que implicações culturais e sociais devem ser sempre reavaliadas devido às mudanças ocorridas pela era digital.

Três das principais mudanças propostas pela virtualidade são: a desvinculação das ideias de acumulação, permanência e integridade patrimonial no meio digital, afetada por uma relação diferente de tempoespaço. Esse paradigma é altamente complexo quando relacionado a um campo tão tradicional como o campo patrimonial, por muito mercantilizado. A produção de singularidades patrimoniais surge na era digital como um fator enriquecedor para a área, mas também desafiante, principalmente para o campo da memória.

Além das apropriações já assimiladas pelo conceito de patrimônio, dentro do ambiente virtual, novas espécies conceituais, ou seja, novos conceitos e categorias são criados, o que só comprova a continua expansão que o conceito desencadeia. Para Dodebei (2008), os próprios adjetivos digital e virtual modificam o conceito de patrimônio de uma forma singular, ao especificá-lo com propriedades próprias da filosofia (virtual) e da Cibernética (digital), apoiado em uma inteligência coletiva, a qual para Lévy (2007) apoia-se no ideal da coletividade inteligente, tornando os indivíduos mais fortes quando unidos, com terreno fértil no ciberespaço.

Assim, bem como acontece com o conceito de cultura, que ao dilatar-se, aumenta a complexidade do entendimento de seu sentido e função, o conceito de patrimônio quando colocado ao lado da virtualidade e da digitalidade também sofre de significação e apreensão de sentido, seja pelo conceito em si, já de difícil delimitação, ou pelos seus adjetivos, que também não compartilham de uma única definição.

Ainda segundo Dodebei (2008), o modo mais compreensível de entender o patrimônio digital é ligá-lo ao conceito de memória documentária, o qual possui uma abstração que reúne os atributos informação/memória/documento, que ao sofrer atualização pela contemporaneidade, leva a compreensão do patrimônio digital como um composto de informações que transitam no ciberespaço. A autora constrói essa relação por meio da organização do conhecimento efetuada pela memória documentária a partir dos dois conjuntos teóricos que lhe dão sustentação. O primeiro conjunto é representado pela Teoria da Informação, que é parte integrante da Cibernética de Wiener (1947) e explicitada pela Teoria Matemática da Comunicação de Shannon (1949). O 
segundo conjunto teórico seleciona das teorias da Memória Social, o conceito de memória virtual em Henri Bergson e o conceito de memória digital em Pierre Lévy (DODEBEI, 2008, p. 2).

Na Carta sobre a Preservação do Patrimônio Digital, a Organização das Nações Unidas para a Educação, a Ciência e a Cultura (UNESCO) (2003), afirma que o patrimônio cultural digital:

[...] consiste de recursos únicos do conhecimento $\mathrm{e}$ expressão humana. Abrange recursos culturais, educacionais, científicos e administrativo, assim como técnicos, legais, médicos e outros tipos de informação criada digitalmente, ou convertida para forma digital a partir de recursos analógicos já existentes. Onde recursos são de 'gênese digital', não há outro formato que não o objeto digital. Materiais digitais incluem textos, bancos de dados, imagens estáticas e em movimento, áudio, gráficos, software e páginas web, dentre uma ampla e crescente variedade de formatos. Eles são geralmente efêmeros e necessitam produção, manutenção e gerenciamento intencional para serem preservados. Muitos desses recursos têm valor e significação duradouros, e, assim, constituem patrimônio que deve ser protegido e preservado para gerações atuais e futuras (UNESCO, 2003, p. 1-2, tradução nossa).

Esse trecho do documento retrata parte do que foi exposto na Conferência Geral da UNESCO, em 17 de Outubro de 2003. A carta visa reconhecer práticas já existentes em âmbito nacional, reafirmando sua importância, a necessidade iminente de preservação, e algumas diretrizes para ação, manifestando a necessidade de os Estados membros, incluindo - Brasil, estabelecerem políticas e ações para salvaguardar o patrimônio digital, cabendo a responsabilidade pela execução à sociedade como um todo, ou seja, instituições de preservação, o setor privado, os meios de comunicação, a sociedade civil, e organizações não-governamentais. O patrimônio digital impõe particularidades da era digital, como 0 engajamento e a conectividade entre pessoas, órgãos de poder e iniciativas privadas.

O que se pode apreender do trecho em destaque é a multiplicidade de áreas socioculturais e formatos de arquivos que são incluídos quando se é gerado o patrimônio em meio digital. Também fica evidente o destaque quanto aos recursos de gênese digital, sem mais uma relação com o objeto original em meio físico. Nesse ambiente, o original é o próprio digital. Esse fator traz uma nova dinâmica para o campo patrimonial e não pode deixar de ser evidenciado, pois a efemeridade do digital, que sofre com constantes atualizações e modificações exige atenção redobrada e atualizada sobre o assunto. Ou seja, o patrimônio, aqui tomado pela informação digital é altamente suscetível de cair tecnicamente em desuso e em inutilidade física. Assim, manter um acesso 
aos recursos informacionais em meio virtual requer um compromisso de longo tempo.

Além do trecho destacado, o documento na íntegra ainda aborda, no artigo nove, sobre a necessidade de disponibilização para acesso de recursos categorizados como patrimônio digital, exaltando a rede mundial e sua potencialidade do ciberespaço de interconectar informações e pessoas, pois

a herança digital é inerentemente ilimitada pelo tempo, geografia, cultura ou formato. É específico da cultura, mas potencialmente acessível a cada pessoa no mundo. Minorias podem falar com maiorias, do indivíduo a uma audiência global. (UNESCO, 2003, p. 2).

Isso, para Stuedahl (2009), marca um novo legado, pois a partir deste momento os recursos digitais de informação e expressão criativa produzidos, distribuídos, acessados e mantidos na forma digital também constituem o patrimônio cultural.

Tal potencialidade do ciberespaço, com foco patrimonial, pode ser visualizada nas redes sociais, principalmente no que diz respeito à disponibilização, divulgação e interconexão de pessoas a novos lugares, culturas e patrimônios. Entretanto, há de se estudar quais memórias e patrimônios estão a se estabelecer com o aumento exponencial das redes sociais, com principal foco nas destinadas a exposição de fotos e vídeos, públicos e privados, como no caso da rede social Instagram. Os patrimônios estão nas redes. Cabe saber até onde vão a disseminação e preservação de sua memória em ambientes digitais, mas com influências particulares de cada usuário que manipula sua própria conta na rede.

\section{Uma memória social cíbrida e fluida}

Diretamente fundamental e relacionada à cultura, desde a Antiguidade, a memória chegou ao século XXI sendo um dos conceitos centrais das Ciências Humanas e Sociais. Desambiguações ocorreram e contribuíram para a origem das classificações da memória, e para cada classificação, uma definição. Conceitos por vezes convergentes, por vezes divergentes, dentre eles: memória individual; memória coletiva; memória de enquadramento; memória social, memória cultural, memória genética, memória emergente etc.

Tendo como premissa a afirmação de Le Goff (2003, p. 419), de que "o conceito de memória é crucial", a memória da qual nos apropriamos na presente pesquisa é aquela do entendimento de Diehl (2002, p. 121): "uma representação daquelas experiências vividas por homens numa dimensão social".

Por meio desse pensamento, alguns autores da área de Ciência da Informação contribuíram com importantes estudos, principalmente no que se refere à memória caracterizada como recurso social e econômico voltada à construção do presente, possibilitando desenvolvimento e avanço social com forte associação ao elemento da informação. Para Monteiro, Carelli e Pickler (2006), devido a esse foco da área, ao tratar a 
memória como instrumento capaz de salvaguardar o passado com visão para o futuro, a preservação se apresenta como a categoria mais utilizada pela Ciência da Informação no tocante à compreensão do objeto memória.

Galindo (2010) corrobora com essa visão quando afirma que devido ao estudo da memória na área se desvencilhar da natureza que a agrega ao sentido de pretérito e associar-se ao senso de matéria corrente e de futuro de modo agregado ao conceito de informação como recurso ou como matéria, revela-se então uma fronteira ainda pouco explorada para a memória como matéria-prima a serviço do desenvolvimento, voltados a uma visão do presente e futuro, com grande ênfase na preservação.

Assim, considerando a interpenetração informação/ memória/ patrimônio, tomada a partir de uma visão semiótica, caracteriza-se pela propriedade da convertibilidade recíproca entre sistemas significantes. A informação nesse contexto é tomada como um signo cujas perspectivas interpretativas se dão por hábito ou convenção (OLIVEIRA, 2009). Essa visão semiótica do fenômeno informacional permite entender a memória como um

[...] conjunto de eventos, fatos, personagens que, através da sua existência no passado, possuem experiências consistentes para o estabelecimento de uma relação da atualidade e o seu passado, quer imediato quer remoto. Essa relação está sempre mediada pela experiência, visto que a memória possui contextualidade [...] A noção de memória está transpassada por um universo simbólico dos mais significativos, mediante um processo de representação no qual são criados referentes para sua cristalização nas consciências, quer individuais quer coletivas, aproximandoa, em muito, da noção de identidade (AZEVEDO NETTO, 2008, p.12).

A memória social possui contextualidade e ocorre de forma dinâmica no tempo e espaço como produção específica dos diferentes grupos sociais. Tal produção é como narrações que emergem dos indivíduos para a sociedade, e vice e versa. Para Bosi (1994, p.88), "a narração é uma forma artesanal de comunicação. Ela não visa a transmitir o 'em si' do acontecido, ela o tece até atingir uma forma boa". Quando fazemos um elo com essa memória e a internet do século XXI obtemos uma potência do real, pois quase não há espaço para narrações negativas nas redes sociais. O mosaico memorial construído pelos indivíduos na rede procura a perfeição, os bons momentos, as mais extraordinárias vivências. As comidas mais belas, os ângulos mais significativos, as vivências mais alegres, mesmo que a comida não esteja boa, que você não seja bem representado naquele ângulo ou que sua vida nem esteja tão feliz. É nesse momento que as realidades se mesclam, a real e a virtual. Os sujeitos contemporâneos são dotados de vidas e memórias cíbridas, online e offline ao mesmo tempo, o que torna toda a nossa realidade social uma realidade também cíbrida. 
Vamos nos pautar na neurociência para exemplificar o real, o qual se constitui de tudo aquilo que está ao alcance dos sentidos sensoriais humanos. Partindo desse pressuposto, Hamdan (2009) afirma que os sinais elétricos, interpretados pelo cérebro humano, nos tornam sujeitos cíbridos, no momento em que a realidade deixa de ser apenas o que vemos, mas tudo aquilo que o nosso cérebro afirma ser real.

Podemos definir assim como cíbrida toda a cultura contemporânea, a qual está pautada pela interconexão das redes e sistemas de modo online e offline. Nesse sentido, segundo Beiguelman (2018) a cultura cíbrida nos insere em um universo cognitivo fundado em um alto grau de instabilidade, capaz de corromper os pressupostos de ordenamento e representação da cultura impressa (analógica), forçando não o seu descarte, mas a redefinição do que se espera da comunicação disseminada em múltiplas plataformas.

Para Domingues e Venturelli (2007) o híbrido vem somar propriedades ao ciber e torna-se cíbrido. Ou seja, o potencial existente no digital é levado ao paroxismo, incrustando virtual com virtual no espaço físico, homologando desejos ficcionais dos sujeitos de viver em mundos paralelos. Objetos, cenas, visualização sintética, geografias misturadas são espaços e lugares cíbridos para a existência.

Essa realidade cíbrida torna a memória ainda mais fluida, no momento em que as redes aumentam as possibilidades de modelagem memorial, de esquecimento intencional e da alteração da realidade analógica. Henriques (2017) nos lembra de que as memórias registradas, mesmo que na internet, não podem ser dissociadas de um processo ficcional, pois não há como o indivíduo recordar e registrar exatamente como aconteceu. $E$, se analisarmos, também não é essa a intenção das redes. A memória é sempre seletiva, contextual e temporal. É assim, para Pêcheux (2007), um espaço móvel de desdobramentos, réplicas, polêmicas e contra discursos, com suas divisões, deslocamentos e retomadas.

Entretanto, a internet revoluciona ainda mais essas memórias registradas, como nos recorda Santaella (2007), ao nos impor um novo tipo de tecnicidade que traz consigo uma linguagem cíbrida, próprio do ciberespaço, que continua a se modificar cotidianamente. Assim, o que constroem as memórias da internet são as relações que os indivíduos constroem, influenciando na narrativa do eu e do outro. Um desencadeamento fluido acontece nesse momento. Ao modelar seus registros memoriais na internet, modelamos as memórias dos nossos amigos, que modelam as dos seus amigos. Condicionamos e somos condicionados pelo espetáculo.

Para Debord (2003), o espetáculo é ao mesmo tempo parte integrante da sociedade, a própria sociedade e seu instrumento de unificação. Tal unificação não se dá apenas pelo conjunto de imagens, mas pela relação social entre as pessoas, mediatizada pelas imagens.

Esse pensamento justifica nossa escolha, pois estudar as redes sociais, bem como as relações dos sujeitos com o ambiente espetacular no 
ciberespaço se faz impetrante para analisar as memórias dos patrimônios culturais digitais que circundam a contemporaneidade. Para tanto, selecionamos a rede Instagram que vem desencadeando impacto na cultura cíbrida, tanto pelo número de usuários como pela intencionalidade no seu uso.

\section{Redes sociais: o caso do Instagram}

O ciberespaço é moldado, em grande parte, pelo conjunto de redes sociais existentes, infligindo diretamente sobre a cultura, ou cibercultura. A quantidade de redes sociais ativas é imensurável, bem como o número de usuários ativos que dialogam cotidianamente nas redes, tecendo novos diálogos culturais.

As redes sociais são estruturas constituídas por sujeitos ou organizações, conectadas por um ou vários tipos de relações, que compartilham valores e objetivos comuns. Seu diferencial se dá na configuração de sua estrutura, de forma aberta, permitindo relacionamentos horizontais e não hierárquicos entre os integrantes. Duarte e Frei (2008) vão além e afirmam que as redes não são apenas outra forma de estrutura, mas quase uma não estrutura, no sentido de que parte de sua força está na habilidade de se fazer e desfazer rapidamente. É a modernidade líquida tomando forma no ciberespaço.

Dentre as mais famosas redes sociais, encontra-se o Facebook, líder de mercado, com mais de 2 bilhões de usuários ativos. Seu impacto foi, e ainda é tão significativo no século XXI, que já se tornou assuntos de variados artigos, teses e dissertações das mais distintas áreas do conhecimento, incluindo a Ciência da Informação. Esse número, contudo, tende a crescer ainda mais devido às novas aquisições efetuadas pelo Facebook, que procurou adquirir outras redes sociais e agregá-las, com o objetivo de sanar os desejos e anseios dos mais variados públicos, pois "os limites das redes não são limites de separação, mas limites de identidade. [...] não é um limite físico, mas um limite de expectativas, de confiança e lealdade, o qual é permanentemente mantido e renegociado pela rede de comunicações" (CAPRA, 2008, p. 22).

Dentre essas aquisições, encontra-se o Instagram, uma rede social destinada à postagem de fotos e vídeos dos usuários. Seu número de usuários já ultrapassa a casa de 1 bilhão, sendo a sétima rede social mais utilizada no mundo e a quinta mais utilizada no Brasil, segundo dados do portal de estatísticas Statista.

Mais do que uma rede social de fotos, o Instagram desponta como um instrumento de mercado, sendo essencial para campanhas e estratégias de marketing. Segundo dados da Content Trends 2016, a rede social que apresentou maior crescimento em adesão pelas empresas foi o Instagram, passando de $42 \%$ de adoção para $47,9 \%$ e se tornando a segunda colocada em preferência pelas marcas no Brasil.

A influência dessa rede tem sido tão significativa para o mercado que cursos de graduação estão sendo criados com o propósito de formar digital influencers, ou influenciadores digitais. O Centro Universitário 
Brasileiro (Unibra), no Recife, anunciou a criação da primeira turma de graduação do curso de Digital Influencers. Tal segmento profissional atua por meio de indivíduos que se disponham a usar determinadas marcas, comer em determinados restaurantes ou ir a determinados lugares, sempre divulgando tais produtos ou segmentos com objetivo de influenciar seus seguidores a também consumir o que ali é apresentado. Bosi (1995, p.2) já dizia que a tecnologia, vem para "multiplicar imagens, multiplicar palavras, multiplicar elementos de informação e multiplicar instrumentos práticos cujo desígnio é abreviar o tempo e poupar esforço, quer o esforço muscular, quer certo tipo de esforço mental, como, por exemplo, o da memória".

Essa rede social por meio dessa influência de mercado revoluciona não apenas a rede social Instagram, mas o modo como às pessoas interagem com as outras nas redes, como vivem suas vidas e como preservam suas memórias. O Instagram pode vir a se tornar o que Debord (2003) chamou de acumulação de espetáculos, onde não há mais vida direta, só fumaças de representações.

Para o campo patrimonial, existe um campo de grande valia no que diz respeito à divulgação e acesso aos patrimônios, tendo em vista a amplitude da disseminação das informações no Instagram. Os mesmos influenciadores digitais que são empregados para aumentar o consumo das grandes empresas, acabam por contribuir para um tipo atual de preservação dos patrimônios digitais: o acesso.

Algumas iniciativas de preservação e acesso já se utilizam do Instagram para fazer valer sua causa, como o Museu Patrimônio Efêmero (@museupatrimonioefemero), que visa criar na rede social um acervo de fotografias de patrimônios brasileiros. A página tem por missão promover uma reflexão sobre o patrimônio cultural brasileiro, realizando uma análise de um acervo fotográfico colaborativo, criado a partir do olhar das pessoas sobre o patrimônio.

Outra iniciativa foi a do Instituto Estadual do Patrimônio e Artístico de Minas Gerais (Iepha-MG) em parceria com o coletivo Nitro Imagens. Juntos realizaram o Circuito Liberdade (@circuitoliberdade), o qual já consta com três edições, com o tema "Meu olhar sobre o patrimônio". O objetivo do concurso foi o de estimular os cidadãos mineiros a construir memórias, registrando objetos de sua história e da cidade onde vive, fortalecendo os conceitos de patrimônio afetivo. No final, todo o material resultou em uma mostra fotográfica que objetivou valorizar a identidade do povo mineiro e seu patrimônio cultural e agora também digital.

\section{Resultados da pesquisa e sua análise}

Buscando entender como as redes relatam as práticas sociais cotidianas e como as memórias sociais dos patrimônios digitais se estabelecem nessa nova configuração espetacular do Instagram, efetuamos uma pesquisa, por meio de um questionário. O universo da pesquisa se deu pelos usuários do Instagram, com uma amostra de jovens e adultos com idade entre 18 e 35 anos. Esse recorte visou incluir duas 
gerações (Y e Z), ou seja, dois perfis distintos, que dialogaram com várias redes sociais no decorrer dos anos, incluindo o Orkut e Facebook, e que vem dando preferência a rede social aqui analisada.

O questionário, do tipo misto, contou com 21 questões. Para conseguir atingir o perfil desejado, o questionário foi aplicado virtualmente com usuários ativos nas redes sociais. A divulgação do questionário se deu por meio de distintas redes, de modo a não privilegiar usuários de determinadas redes sociais em detrimento de outras. Foram coletadas 130 respostas com o perfil desejado (geração $Y$ e $Z$ ), sendo 89 indivíduos do gênero feminino e 41 do gênero masculino, prevalecendo as idades entre 25 e 28 anos, as quais estão ainda mais atuantes nas redes sociais.

Gráfico 1 - Idade dos Sujeitos

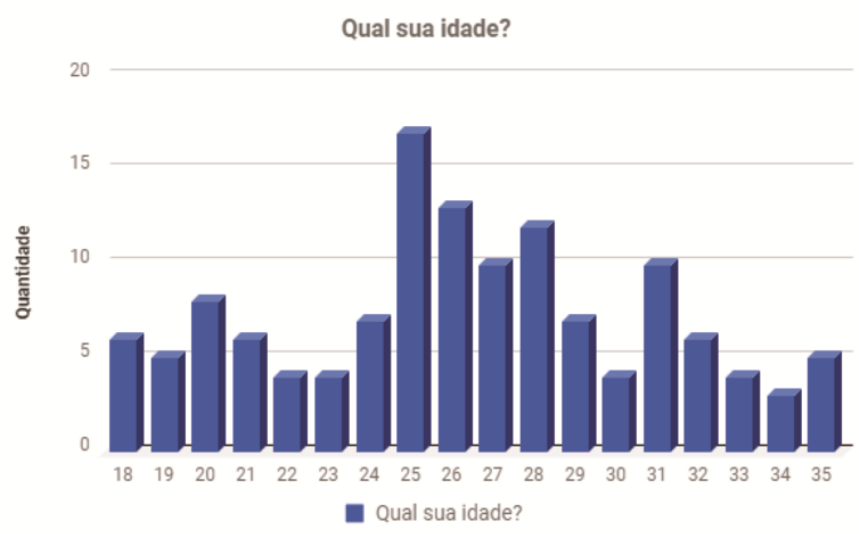

Fonte: dados da pesquisa (2017)

Gráfico 2 - Acesso à Internet

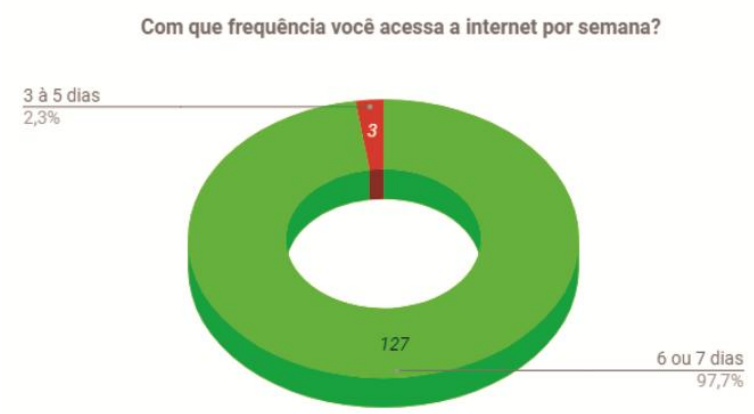

Fonte: dados da pesquisa (2017)

Podemos confirmar a partir dos dados coletados, a nossa convicção de que as redes sociais não são mais ocasionais ou até mesmo opcionais para o perfil entrevistado, mas sim uma constante que molda seu cotidiano, suas atividades e suas memórias. As redes sociais tornaram-se 
parte da cultura dominante, ou mais especificamente, dominam a cibercultura.

No decorrer dos dias em que os sujeitos afirmam se utilizarem da internet, seis redes sociais se destacam quanto ao acesso para troca ou compartilhamento de mensagens (escrita, som ou imagem) respectivamente, por ordem de utilização: Whatsapp, Instagram, Facebook, E-mail, Messenger e Twitter. Assim, para os sujeitos da pesquisa, três redes sociais já se encontram obsoletas e sem interesse ativo: Hangouts, Google+ e Skype.

Dentre as seis redes de destaque, o Facebook e Whatsapp despontam como preferenciais para o compartilhamento de notícias, enquanto o Instagram desponta como principal opção para postagem de fotos particulares e públicas, além de ser a primeira opção para descobrir novas opções de estabelecimentos de compra, lazer, alimentícios e culturais para mais de $67 \%$ dos entrevistados.

Quando analisamos esses números, vemos que a quantidade de postagens as quais englobam patrimônios culturais (tombados ou não) aumenta exponencialmente, pois há explicita necessidade de postar onde o sujeito de encontra e o que está fazendo.

O próximo questionamento acabou por comprovar essa análise. Questionados sobre o conteúdo das postagens, dos 130 entrevistados, $124(95,4 \%)$ afirmam, além de serem usuários ativos do Instagram, já terem postado imagens ou vídeos de parques, museus, teatros, exposições, cinema, eventos ou locais culturais. Além disso, 123 entrevistados afirmam que seguem personalidades públicas, influenciadores digitais e estabelecimentos culturais. Dentre esses usuários, 96 afirmam que já consumiram algo ou foram a algum lugar porque viram no Instagram e outros 16 afirmam que pretendem.

Esses números retomam nosso questionamento sobre o impacto que os sujeitos (e as empresas que investem nesse nicho) ocasionam dentro de suas redes sociais, influenciando seus seguidores a visitarem os mesmos lugares, ou seja, consumirem de sua cultura. É uma cultura cíbrida, como afirmamos, pois o que os sujeitos vivenciam online afeta diretamente sua vida offline e é parte constituinte de sua memória social. Esses dados nos remetem ao pensamento de Hamdan (2009), quando afirma que os sinais elétricos, interpretados pelo cérebro humano, nos tornam sujeitos cíbridos, no momento em que a realidade deixa de ser apenas o que vemos, mas tudo aquilo que o nosso cérebro concebe como real. Considerando que sujeitos cíbridos fazem parte de uma cultura contemporânea, a qual está pautada pela interconexão das redes e sistemas de modo online e offline.

Corroborando, Beiguelman (2018) diz que essa realidade insere os sujeitos em um mundo cognitivo procedente de certo grau de instabilidade, capaz de falsear os pressupostos de ordenamento e representação da cultura impressa (analógica), forçando não o seu término, mas a redefinição do que se espera da comunicação disseminada em múltiplas plataformas. 
Uma das questões por nós enfatizadas foi o uso do Instagram. Nesse sentido, nossos respondentes se pronunciaram assim (Gráfico 3):

Gráfico 3: Influência no Instagram

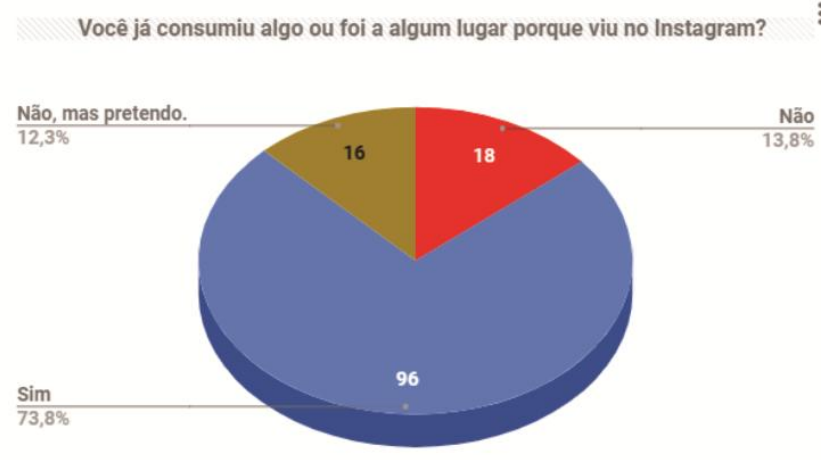

Fonte: dados da pesquisa (2017)

Ainda diretamente relacionado à memória, podemos analisar a influência do Instagram, e classificá-lo como agente de memória contemporânea, fato o qual se mostra evidente quando os entrevistados afirmam que a principal finalidade de suas fotos cotidianas é a postagem na rede das fotos mais importantes $(76,9 \%)$, além da postagem nas redes (incluindo o atual mecanismo dos stories) $(22,3 \%)$, como podemos verificar no gráfico 4.

Além disso, 97 entrevistados afirmam que para eles a principal função do Instagram é o registro da memória cotidiana. Em seguida, os entrevistados acreditam que quando suas fotos são postadas, os usuários desejam, em ordem de importância, após o registro da memória:
a) curtidas;
b) comentários;
c) que as pessoas saibam onde eles estão e
d) que as pessoas repercutam, na rede e fora da rede, suas postagens.

Esses dados traduzem o pensamento o qual mencionamos de Debord (2003), onde o espetáculo é ao mesmo tempo parte integrante da sociedade, a própria sociedade e seu instrumento de unificação. 
Gráfico 4 - Destino das fotos

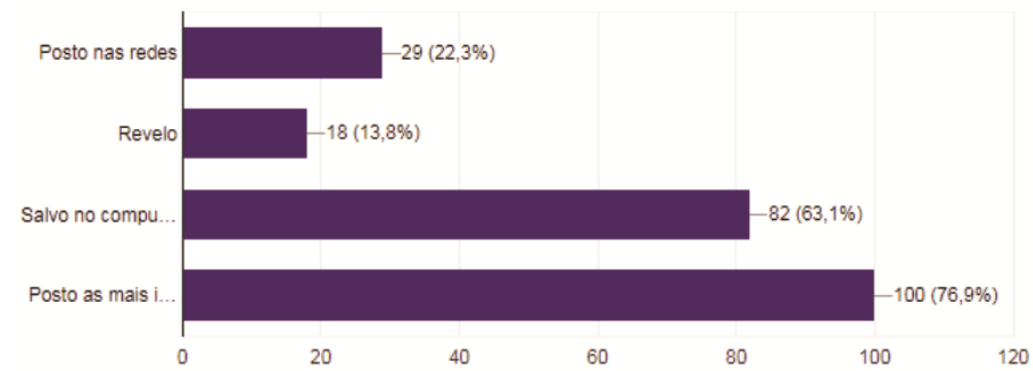

Fonte: dados da pesquisa (2017)

Gráfico 5 - Memória Fluida do Instagram

Você já apagou postagens feitas anteriormente no Instagram?

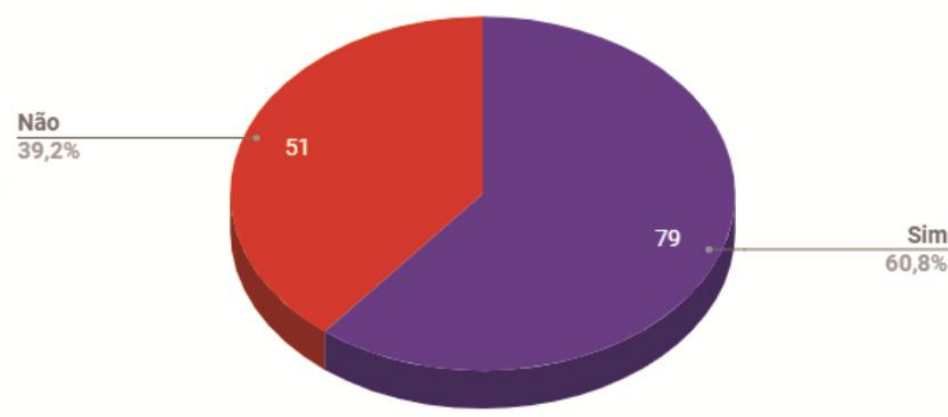

Fonte: dados da pesquisa (2017)

Entretanto, podemos voltar aos nossos questionamentos teóricos e comprovar que as redes tornam a memória ainda mais efêmera, pois apesar do maior número de sujeitos afirmarem que o Instagram serve, em primeira instância, para registro da memória, mais de $60 \%$ dos entrevistados afirmam já terem apagado suas fotos compartilhadas anteriormente na rede, como podemos ver no Gráfico 5. Dentre as justificativas destacam-se as voltadas à mudança de opinião quanto à importância daquele registro na memória de sua rede social, a antiguidade da foto ou por estarem feias. Em outras linhas, não há um valor agregado duradouro para muitos, valor esse o qual é essencial para a preservação da memória, como bem observamos no pensamento de Chagas (2005), onde é preciso que o sujeito da ação identifique no objeto a ser preservado algum valor para que haja preservação efetiva.

Essa análise comprova o mais uma vez o pensamento de Beiguelman (2018), quando cita a instabilidade cognitiva que as redes impõem aos sujeitos pela redefinição da comunicação entre a sociedade e a construção de sua identidade, pautada na sua memória social construída. Ressaltamos que os registros memoriais e seu impacto, aqui analisados pelo questionário e representados nos gráficos, são 
constituídos de informações digitais, linha de pensamento a qual se apoia em Dodebei (2011), como mencionamos em nosso referencial. Devido à materialidade das informações digitais, são estas constituintes, inclusive, como parte da cultura material, podendo ascender a categoria de patrimônios culturais digitais, tomando as visões antropológicas compartilhadas por Geertz (1978), Laraia (2001), Lemos (2002), Castells (2007) e Lévy (2007).

\section{Considerações finais}

O regime de informação do patrimônio cultural digital existente no ambiente virtual é distinto do real ordinário e ainda não foi claramente dito à sociedade, científica ou não. Seus pontos não ditos permanecem como um desafio à área da Ciência da Informação que se ocupa dos fenômenos informacionais em ambientes específicos, produzidos pelo homem.

Assume-se ao longo deste trabalho que o patrimônio é uma representação responsável pela preservação da memória, tornando-a menos efêmera além de ser passível de ações políticas de preservação. Apenas quando o objeto é considerado patrimônio é que se enquadra dentro de políticas e iniciativas propostas e torna-se possível de ser salvaguardado. Contudo, a apropriação do patrimônio digital ainda é difusa e não consensual, mesmo dentro da CI.

Uma das questões mais importantes, quando está em debate o patrimônio cultural da sociedade são as iniciativas e políticas que visam seu desenvolvimento, acesso e preservação. Todos os aspectos sociais que têm por finalidade benefícios coletivos são, em essência, responsabilidade do governo e de iniciativas públicas, estas, quando não são revistas, acabam por não contribuir com aspectos contemporâneos. Contudo, grande parte do respaldo cabe à comunidade científica e à importância direcionada a determinados temas e segmentos. Quando incluímos os patrimônios à informação digital, novos micro poderes surgem atrelados aos sujeitos, que são agentes e agenciadores, além de responsáveis por preservar, disseminar e perpetuar a memória social advinda dos patrimônios.

Tais sujeitos na contemporaneidade têm contribuído significativamente para um novo tipo de preservação do patrimônio digital, por meio da disseminação e do acesso, principalmente por fotos ou imagens. As redes sociais ampliaram esse poder agenciador dos sujeitos, na medida em que aniquila o tempo e o espaço, tornando tudo passível de acesso ao apertar de um click.

A pesquisa aqui realizada com os usuários da rede social Instagram procurou entender como se dá relação dos indivíduos com a rede e a memória que se constitui nesse processo. Ficou clara a importância da postagem de fotos para os entrevistados, sejam elas fotos particulares ou de lugares públicos, de lazer, compras ou culturais. Assim, confirma-se o pensamento de que no Instagram existe um lugar de memória e que esse lugar se configura como um lugar de preservação dos patrimônios digitais 
por meio da divulgação e acesso que as conexões estabelecidas entre os usuários permitem. A facilidade de postar e encontrar patrimônios são uns dos muitos benefícios que as redes sociais agregam ao campo patrimonial.

Entretanto, de certo modo, a importância destinada ao acesso às redes é tão significativa para os usuários que, como apontou a pesquisa, não há espaço para o desatualizado e o feio. As novas relações estabelecidas no ciberespaço requerem curtidas, comentários e repercussão, cibridamente. Se a memória ali representada não for capaz de trazer isso, ela facilmente é deletada. Nesse sentido, o diálogo entre a memória e o esquecimento torna-se ainda mais evidente na modernidade líquida das redes sociais.

Assim, ainda é necessária uma revisão da apropriação conceitual do patrimônio cultural digital e a ressonância das atuais práticas de preservação e acesso, levando em consideração as mudanças proporcionadas pela contemporaneidade fluida do digital. As redes sociais são um avanço no acesso, mas não deixam de ser passageiras e espetaculosas. Hoje podem despontar como auxiliar a preservação e acesso aos patrimônios, mas as informações digitais ali constantes estão à mercê da vontade dos sujeitos, os quais estão ainda por definir suas identidades e necessidades.

\section{Referências}

ABREU, Regina. Patrimonialização das diferenças e os novos sujeitos de direito coletivo no Brasil. In: TARDY, Cécile; DODEBEI, Vera. (Org.). Memória e Novos Patrimônios. Marseille: OpenEdition Press, 2015. v. 1, p. 67-93.

AZEVEDO NETTO, Carlos Xavier de. Preservação do patrimônio arqueológico: reflexões através do registro e transferência da informação. Ciência da Informação, Brasília, DF, v.37, n. 3, p. 7-17, set./dez. 2008.

BARBOSA, Marialva. Memória e tempo: arcabouços do sentido da contemporaneidade. Ciberlegenda, n. 1, 1998.

BAUMANN, Zygmunt. Modernidade líquida. Rio de Janeiro: Jorge Zahar, 2001.

BEIGUELMAN, Giselle. Está chegando a cultura cíbrida: expansão das redes sem-fio aponta para revisão dos paradigmas de leitura, rede e comunicação. Revista Trópico, São Paulo, 2018. Disponível em:

http://www.revistatropico.com.br/tropico/html/textos/1634,1.shl. Acesso em: 22 ago. 2019.

BELLOTTO, Heloísa Liberalli. Arquivo: estudo e reflexões. Belo Horizonte: Editora UFMG, 2014. 
BOSI, Alfredo. Considerações sobre o tempo e informação. São Paulo: IEA, 1995.

BOSI, Ecléa. Memória e sociedade: lembrança de velhos. 7. ed. São Paulo: Companhia das Letras, 1994.

CAPRA, Fritjof. Vivendo redes. In: DUARTE, Fábio; QUANDT, Carlos; SOUZA, Queila. O tempo das redes. [S.I.]: Perspectiva, 2008.

CAPURRO, Rafael; HJORLAND, Birger. O conceito de informação. Perspectivas em Ciência da Informação, Belo Horizonte, v. 12, n. 1, p. 148-207, abr. 2007.

CASTELLS, Manuel. Sociedade em rede: a era da informação: economia, sociedade e cultura. São Paulo: Paz e Terra, 2007.

CHAGAS, Mário. Memória política e política de memória. In: ABREU, Regina; CHAGAS, Mário (Org.). Memória e patrimônio: ensaios contemporâneos. Rio de Janeiro: DP\&A: FAPERJ: UNI-RIO, 2003. p. 141171.

CHAGAS, Mário. Casas e portas da memória e do patrimônio. In: GONDAR, Jô; DODEBEI, Vera (Org.). O que é memória social? Rio de Janeiro: Contracapa, 2005. p.115-132.

CHOAY, Françoise. A alegoria do patrimônio. São Paulo: Estação Liberdade: Editora UNESP, 2006.

DEBORD, Guy. A sociedade do espetáculo. [S.l.]: Coletivo Periferia, 2003.

DELEUZE, Gilles; GUATTARI, Félix. Mil platôs: esquizofrenia e capitalismo. São Paulo: Editora 34, 1995. v. 1-2.

DIEHL, Astor Antônio. Cultura historiográfica: memória, identidade e representação. São Paulo: EDUSC, 2002. 222 p. (Coleção Histórica).

DODEBEI, Vera. Patrimônio digital virtual: herança, documento e informação. In: REUNIÃO BRASILEIRA DE ANTROPOLOGIA, 26, 2008, Porto Seguro. Anais [...]. São Paulo: Associação Brasileira de Antropologia, 2008. v. 1. p. 1-12.

DODEBEI, Vera. Cultura digital: novo sentido e significado de documento para a memória social? DataGramaZero - Revista de Ciência da Informação, [s.l.], v.12, n.2, abr. 2011.

DOMINGUES, Diana; VENTURELLI, Suzete. Cibercomunicação cíbrida no continuum virtualidade aumentada e realidade aumentada: era uma vez ... a realidade. ARS (São Paulo), São Paulo, v. 5, n. 10, p. 108-121, 2007. Disponível em: 
http://www.scielo.br/scielo.php?script=sci arttext\&pid=S1678-

53202007000200011\&lng=en\&nrm=iso. Acesso em: 22 ago. 2019.

DUARTE, Fábio; FREI, Klaus. Redes urbanas. In: DUARTE, Fábio; QUANDT, Carlos; SOUZA, Queila. O tempo das redes. [S.I.]: Editora Perspectiva, 2008.

GALINDO, Marcos. Tecnologia \& memória. Revista do Instituto de Estudos Brasileiros, [s.l.], v. 50, p. 179-190, 2010.

GANTZ, John. The diverse and exploding digital universe: an updated forecast of the worldwide information growth through 2011. [S.I.]:

International Data Corporation (IDC), 2008.

GANTZ, John; REINSEL, David. The digital universe in 2020: Big Data, nigger digital shadows, and biggest growth in the far east. New York: IDC, 2012.

GEERTZ, Clifford. A Interpretação das culturas. Tradução de Fanny Wrolbel. Rio de Janeiro: Zahar, 1978.

GONDAR, Jô. Quatro proposições sobre memória social. In: Gondar, Jô; Dodebei, Vera. (Org.). O que é memória social? Rio de Janeiro:

Contracapa, 2005. v. 1, p. 11-26.

HAMDAN, Camila. Ecologia Cíbrida: arte, tecnologia e sistemas vivos. In: SEMINARIO NACIONAL DE PESQUISA EM CULTURA VISUAL, 2., 2009, Goiania. Anais[...] Goiânia: UFG, Goiânia, 2009. Disponível em: https://www.academia.edu/300741. Acesso em: 19 nov. 2019

HENRIQUES, Rosali Maria Nunes. Narrativas, patrimônio digital e preservação da memória no Facebook. Revista Observatório, Palmas, v. 3, n. 5, p.123-146, ago. 2017.

LARAIA, Roque de Barros. Cultura: um conceito antropológico, 14. ed. Rio de Janeiro: Zahar, 2001.

LAZZARIN, Fabiana; AZEVEDO NETTO, Carlos Xavier; SOUSA, Marckson Roberto. Informação, memória e ciberespaço: considerações preliminares no campo da Ciência da Informação no Brasil. TransInformação, Campinas, v. 27, n. 1, p. 21-30, jan./abr. 2015.

LE COADIC, Yves-François. A Ciência da Informação. Tradução de Maria Yeda F. S. de Filgueiras Gomes. Brasília, DF: Briquet de Lemos/Livros, 2004.

LE GOFF, Jaques. História e memória. 5. ed. Campinas: Unicamp, 2003.

LEMOS, André. Cibercultura. Porto Alegre: Sulina, 2002. 
LÉVY, Pierre. Cibercultura. São Paulo: Editora 34, 2007.

MARTELETO, Regina Maria. Cultura informacional: construindo o objeto informação pelo emprego dos conceitos de imaginário, instituição e campo social. Ciência da Informação, Brasília, v. 24, n. 1, p. 89-93, jan./abr. 1995.

MONTEIRO, Silvana; CARELLI, Ana; PICKLER, Maria Elisa. Representação e memória no ciberespaço. Ciência da Informação, Brasília, DF, v. 35, n. 3, p. 115-123, set./dez. 2006. Disponível em:

http://www.scielo.br/pdf/ci/v35n3/v35n3a11.pdf. Acesso em: 25 ago. 2017.

OLIVEIRA, Lizete Dias de. Arte rupestre como signo: uma abordagem semiótica do fenômeno infocomunicacional. In: CONGRESSO INTERNACIONAL DE ARTE RUPESTRE: GLOBAL ROCK ART, 2009, Piauí. Anais [...]. [S.I.]: IFRAO: Global Rock Art. 2009.

PÊCHEUX, Michel. Papel da memória. In: PÊCHEUX, Michel. Papel da memória. Campinas: Pontes, 1999, p. 49-56.

PINTO, Maria Manuela Gomes de Azevedo. PRESERVMAP: um roteiro da preservação na era digital. Porto: Afrontamento, 2009.

SANTAELLA, Lucia. As linguagens como antídoto ao midiacentrismo. MATRIZes, São Paulo, ano 1, n. 1, p. 75-97, jul./dez. 2007.

SCHWARTZMAN, Simon. A redescoberta da cultura. São Paulo: Edusp, 1997.

SIEBRA, Sandra de Albuquerque; BORBA, Vildeane da Rocha; MIRANDA, Májory Karoline Fernandes de Oliveira. Curadoria digital: um termo interdisciplinar. Informação \& Tecnologia (ITEC), João Pessoa, v. 3, n. 2, p. 21-38, jul./dez. 2016.

SILVA, Armando Malheiro da. A informação: da compreensão do fenómeno e construção do objeto científico. Porto: Afrontamento, 2006.

STUEDAHL, Dagny. Digital cultural heritage engagement: a new research field for ethnology. Ethnologia Scandinavica, [s.l.], v. 39, p. 67-81, 2009.

UNESCO. Charter on the preservation of the digital heritage. [S.I.]: UNESCO, 2003. Disponível em: http://portal.unesco.org/en/ev.phpURL ID $=17721 \&$ URL DO=DO TOPIC\&URL SECTION=201.html. Acesso em: 26 ago. 2017. 